\title{
Políticas públicas de comunicação na Constituição de 1988: avanços, retrocessos e desafios futuros ${ }^{1}$
}

\section{Las políticas públicas de comunicación en la Constitución Brasileña de 1988: avances, retrocesos y desafíos futuros \\ Public policies of communication in the Brazilian Constitution of 1988: advances, setbacks and future challenges}

\author{
Carlo José Napolitano \\ Universidade Estadual Paulista (Brasil) \\ carlo.napolitano@unesp.br \\ Tatiana Stroppa ${ }^{3}$ \\ Instituição Toledo de Ensino (Brasil) \\ tatianastroppa@hotmail.com
}

Fecha de recepción: 16 de agosto de 2019

Fecha de recepción evaluador: 21 de agosto de 2019

Fecha de recepción corrección: 29 de agosto de 2019

\begin{abstract}
1 Uma primeira versão deste texto foi publicada na obra coletiva impressa "A evolução do sistema constitucional de garantias de direitos nos 30 anos da Constituição Federal de 1988. 1ed. Bauru: Editora Spessotto, 2018, pp. 367-380." $\mathrm{O}$ texto está vinculado à pesquisa "Políticas públicas de comunicação no Supremo Tribunal Federal: a liberdade de expressão em julgamento", financiada pela Chamada Universal - MCTI/CNPq n. 1/2016 - Faixa A do Conselho Nacional de Desenvolvimento Científico e Tecnológico - CNPq.

2 Carlo José Napolitano. Professor Associado da Universidade Estadual Paulista, Departamento de Ciências Humanas e do Programa de Pós-Graduação em Comunicação, da Faculdade de Arquitetura, Artes e Comunicação, Bauru/SP, Livre-Docente em Direito à Comunicação, Pós-Doutor pelo Departamento de Direito do Estado, da Faculdade de Direito, da Universidade de São Paulo, Doutor em Sociologia pelo Programa de Pós-Graduação em Sociologia da Faculdade de Ciências e Letras, /Araraquara. https://orcid.org/0000-0002-6328-6398
\end{abstract}

3 Tatiana Stroppa. Doutoranda em Direito e Mestre em Direito pelo Programa de Pós-graduação stricto sensu Instituição Toledo de Ensino (2006), professora de Direito Constitucional e de Direito Processual Constitucional do Curso de Direito do Centro Universitário de Bauru e da Faculdade Iteana de Botucatu, advogada e bolsista de treinamento técnico na pesquisa denominada "Políticas públicas de comunicação no Supremo Tribunal Federal: a liberdade de expressão em julgamento", financiada pela Chamada Universal - MCTI/CNPq n. 1/2016 - Faixa A do Conselho Nacional de Desenvolvimento Científico e Tecnológico - CNPq. https://orcid.org/0000-0002-3456-7588 


\title{
Resumo
}

O presente trabalho é parte integrante de pesquisa que investiga decisões do Supremo Tribunal Federal relacionadas às políticas públicas de comunicação, em especial, aquelas que tratam da liberdade de expressão do pensamento. Este artigo, de natureza bibliográfica e documental, visa especificamente analisar as políticas públicas de comunicação previstas no texto constitucional de 1988, no intuito de indicar os avanços, criticar os retrocessos e apontar os problemas e os desafios constitucionais brasileiros relativos a essas políticas públicas, concluindo que a anomia do setor configura-se um retrocesso e que a regulação das normas constitucionais é um desafio para o amadurecimento democrático da sociedade brasileira.

Palavras-chave: políticas públicas de comunicação, constituição federal, desafios constitucionais.

\section{Resumen}

Este artículo es una parte integral de la investigación que estudia las decisiones del Tribunal Supremo Federal relacionadas con las políticas de comunicación pública, especialmente las que se ocupan con la libertad de expresión del pensamiento. Este artículo, de naturaleza bibliográfica y documental, pretende específicamente analizar las políticas públicas de comunicación previstas en el texto constitucional de 1988, a fin de indicar los avances, criticar los reveses y señalar los problemas y desafíos constitucionales brasileños relacionados con estas políticas públicas. Concluye que la anomia del sector aparece como un retroceso y que la regulación de las normas constitucionales es un desafío para la maduración democrática de la sociedad brasileña.

Palabras clave: políticas de comunicación pública, constitución federal, desafíos constitucionales.

\begin{abstract}
This text is part of ongoing research that investigates Brazilian Supreme Court decisions related to the public policies communications, especially those that deal with the freedom of speech. This paper, supported by bibliographical and documental research, specifically aims to analyze the public policies communication forecasted in the 1988 constitutional text, in order to indicate the advances, criticize the setbacks and point out the Brazilian constitutional problems and challenges related to these public policies, concluding that the anomie of this sector is a setback and that the regulation of constitutional norms is a challenge is a challenge for the democratic maturation of Brazilian society.
\end{abstract}

Keywords: public policies communication, brazilian constitution, constitutional challenges. 


\section{Introdução}

O presente trabalho tem por objetivo descrever os avanços, criticar os retrocessos e apontar os problemas e os desafios futuros relacionados às políticas públicas de comunicação previstas na Constituição Brasileira de 1988.

Especificamente, este texto visa analisar as políticas públicas de comunicação previstas pela ordem constitucional de 1988, aquelas que já foram implementadas legalmente, bem como aquelas que ainda não reguladas legalmente ou foram desfiguradas por ações ou inações estatais.

O presente estudo, decorrente de pesquisa bibliográfica e documental, de natureza dedutiva, sobre assuntos correlatos à temática está assim estruturado: nas primeiras três seções serão indicadas pontualmente as políticas públicas de comunicação previstas no texto constitucional, aquelas que foram implementadas legalmente até o presente e, em uma análise crítica, as que ainda dependem de implementação e as que foram desfiguradas por ações ou inação do Estado brasileiro, a saber, pelo Executivo, Legislativo e Judiciário e, por fim, apresentam-se alguns apontamentos em sede de conclusão, considerando que a regulamentação legal do setor da comunicação social é um desafio constitucional do Estado brasileiro.

\section{Referencial teórico-metodológico e Discussão}

\section{Políticas públicas de comunicação previstas no texto de 1988}

Inicialmente cumpre destacar que a pesquisa da qual resulta este trabalho parte do pressuposto que a análise jurídica das políticas públicas coloca as ações do Estado e do governo como lócus privilegiado nesta seara, independentemente do ramo do direito que observa a questão - constitucional, administrativo, econômico, por exemplo (Napolitano, 2017). Essa premissa está amparada na literatura nacional acerca da temática e que considera a política pública como um programa de ação governamental mediado pelo direito (Grau, 2003, Bucci, 2006, 2008 e 2013, Coutinho, 2013).

O direito nesse sentido seria, de acordo com Coutinho (2013), o objeto das políticas públicas, ou em outros termos, a fonte definidora das políticas públicas. Também se considera que o direito estabelece o arranjo institucional, regulando procedimentos, articulando atores relacionados à colocação em prática de uma determinada política pública. Estabelece ainda os meios para se chegar aos fins pré-determinados, bem como prevê mecanismos de vocalização de demandas de determinadas políticas públicas.

Toma-se ainda, como uma premissa da pesquisa, que uma das particularidades da Constituição de 1988 reside no fato de nela estarem previstos diversos assuntos de natureza econômica. No que diz respeito especificamente à Comunicação Social, a Constituição de 05 de outubro de 1988 foi generosa na sua regulação. Em vários pontos do texto constitucional a temática das políticas públicas de comunicação está presente. 
Nesse sentido e de acordo com Napolitano (2017), vários exemplos relacionados aos suportes constitucionais das políticas públicas de comunicação podem ser mencionados.

Na Constituição estão dispostas no Título VIII, Capítulo V (artigos 220 a 224), que trata da Comunicação Social quanto às diretrizes básicas acerca dessas políticas públicas, muito embora outras orientações possam ser identificadas no texto constitucional, como é o caso, por exemplo, da possibilidade de restrições de concessão de emissora de rádio e televisão para políticos detentores de mandato eletivo, conforme artigo 54 da CF. No entanto, este texto ficará circunscrito ao tópico mencionado da Constituição lócus de várias dessas diretrizes, conforme segue.

O Artigo 220, $\S 3^{\circ}$ dispõe que compete à lei federal: I - regular as diversões e espetáculos públicos, cabendo ao Poder Público informar sobre a natureza deles, as faixas etárias a que não se recomendem, locais e horários em que sua apresentação se mostre inadequada; II - estabelecer os meios legais que garantam à pessoa e à família a possibilidade de se defenderem de programas ou programações de rádio e televisão que contrariem o disposto no art. 221, bem como da propaganda de produtos, práticas e serviços que possam ser nocivos à saúde e ao meio ambiente. $\mathrm{O} \S 4^{\circ}$ disciplina que a propaganda comercial de tabaco, bebidas alcoólicas, agrotóxicos, medicamentos e terapias estará sujeita a restrições legais, nos termos do inciso II do parágrafo anterior, e conterá, sempre que necessário, advertência sobre os malefícios decorrentes de seu uso. Por sua vez, o $\S 5^{\circ}$ estabelece que os meios de comunicação social não podem, direta ou indiretamente, ser objeto de monopólio ou oligopólio.

O artigo 221 estabelece princípios para a produção e a programação das emissoras de rádio e televisão, tais como: I - preferência a finalidades educativas, artísticas, culturais e informativas; II - promoção da cultura nacional e regional e estímulo à produção independente que objetive sua divulgação; III - regionalização da produção cultural, artística e jornalística, conforme percentuais estabelecidos em lei; IV - respeito aos valores éticos e sociais da pessoa e da família.

O artigo 222 estabelece que a propriedade de empresa jornalística e de radiodifusão sonora e de sons e imagens é privativa de brasileiros natos ou naturalizados há mais de dez anos, ou de pessoas jurídicas constituídas sob as leis brasileiras e que tenham sede no País.

O artigo 223 atribui competência ao Poder Executivo para a outorga e renovação de concessão, permissão e autorização para o serviço de radiodifusão sonora e de sons e imagens, observado o princípio da complementaridade dos sistemas privado, público e estatal e estabelece também a participação do Congresso Nacional nesse processo.

Por fim, apenas com o objetivo de exemplificar, o artigo 224 trata do Conselho de Comunicação Social, órgão auxiliar do Congresso Nacional para as políticas públicas de comunicação. 
Em uma leitura atenta do Título VIII, Capítulo V da Constituição extrai-se que o texto constitucional determinou a edição de 7 (sete) leis federais para a regulação e implementação de políticas públicas de comunicação. Nas seções que seguem serão indicadas e analisadas aquelas que foram implementadas legalmente, as que ainda dependem de regulação e outras que foram desconfiguradas por ações do Executivo, Legislativo e Judiciário brasileiro, nos últimos anos.

\section{Políticas públicas implementadas legalmente}

Das sete exigências constitucionais de elaboração de leis no capítulo da comunicação social, apenas cinco (5) foram editadas até o momento da elaboração deste trabalho, algumas delas regulando a matéria apenas parcialmente.

Em ordem cronológica, trata-se das seguintes leis: 1 - lei 8.389/91, que criou o Conselho de Comunicação Social previsto no artigo 224 da Constituição; 2 - lei 9.294/96, que regula parcialmente o artigo $220, \S 4^{\circ}$, da CF disciplinando as restrições ao uso e à propaganda de produtos fumígeros, bebidas alcoólicas, medicamentos, terapias e defensivos agrícolas; 3 - lei 10.359/2001, que dispõe sobre a obrigatoriedade de aparelhos de televisão conterem dispositivo que possibilite o bloqueio temporário de recepção de programação inadequada, regulando parcialmente o artigo $220, \S 3^{\circ}$, II da CF; 4 - lei 10.610/2002, que trata da participação de capital estrangeiro em empresas de comunicação, previsto no artigo $222, \S 4^{\mathrm{o}}$ da CF; 5 - lei 12.485/2011 que dispõe sobre a comunicação audiovisual de acesso condicionado, regulamentando o parágrafo $3^{\circ}$, do artigo 222. Em face dessa lei houve a propositura de quatro ações diretas de inconstitucionalidades reunidas e relatadas pelo Min. Luiz Fux: a ADI 4679, e que foi julgada procedente em parte, apenas para declarar a inconstitucionalidade material do art. 25 da Lei $n^{\circ}$ 12.485/2011; as ADI 4747, 4756 e 4923 que tiveram os pedidos julgados integralmente improcedentes.

Considera-se também aqui que o artigo 221 - III pode ser considerado regulado pela lei 4.117/62, conhecida como Código Brasileiro de Telecomunicações, no que diz respeito aos percentuais de regionalização da produção cultural, artística e jornalística das emissoras de rádio e televisão.

Na seção que segue serão apontadas as políticas ainda não reguladas por lei e aquelas que foram desfiguradas por ações ou inações estatais. 


\section{Políticas públicas não reguladas legalmente ou desfiguradas por ações ou inações estatais}

Desde a edição da Constituição, há trinta anos, algumas políticas públicas vinculadas à comunicação social não foram reguladas legalmente, outras o foram apenas parcialmente e outras foram desfiguradas por ações ou inações do Estado brasileiro.

Observe-se que até o julgamento da Arguição de Descumprimento de Preceito Fundamental (ADPF) n ${ }^{\circ}$ 130, em 2009, a lei 5.250/67 (Lei de Imprensa) regulava de forma genérica pontos atinentes à liberdade de expressão e liberdade de informação jornalística como, por exemplo: regras para registro dos meios de comunicação, direito de resposta ${ }^{\mathrm{i}}$, responsabilização civil e penal por abusos no exercício das referidas liberdades.

Declarada, portanto, a incompatibilidade integral da lei 5.250/67 com a Constituição, não há no Brasil uma legislação única que verse sobre a Comunicação Audiovisual e promova a regulação, fiscalização, fomento e a promoção de instrumentos voltados à diversificação das atividades informativas e culturais.

Além dessa lei geral, a regulação da classificação indicativa prevista no artigo $220, \S 3^{\circ}$, I, pode ser considerada um exemplo de ausência de regulação legal ${ }^{\mathrm{ii}}$. O segundo exemplo é a atualização da regulação do artigo 221, III, que conta com regramento, como já visto, contudo, da década de 1960.

Outras políticas foram reguladas apenas parcialmente, como é o caso da possibilidade de restrição de propaganda de bebidas alcoólicas. Parcialmente, pois a lei n 9.294/96 considera bebidas alcoólicas, para efeitos de restrição de propaganda, aquelas que contenham percentual alcoólico acima $13^{\circ}$ Gay Lussac, excluindo-se das restrições as bebidas abaixo dessa gradação, como é o caso das cervejas.

Mesmo a despeito da não exigência expressa de edição de lei reguladora de determinadas políticas públicas de comunicação e por considerá-las aqui como de aplicação imediata, poderiam ser citadas lacunas legais referentes, por exemplo, à definição de regras claras sobre a proibição de monopólio e oligopólios nos meios de comunicação, conforme previsão do artigo $220, \S 5^{\circ}$ da CF.

Destaque-se, no entanto, que há singelos limites para as outorgas de concessão ou permissão para execução de serviço de radiodifusão estipulados no Art. 12 do DecretoLei 236/67. Tal legislação busca restringir a concentração ao prever uma limitação máxima, por entidade, de 10 (dez) outorgas de estações radiodifusoras em todo o território nacional, sendo no máximo 5 (cinco) em VHF e 2 (duas) por Estado (artigo 12, caput), o que representa um limite ao alcance territorial da transmissão de sinais e, consequentemente, à audiência das emissoras. Neste limite não devem ser consideradas, porém, as estações repetidoras e retransmissoras de televisão pertencentes às estações geradoras (artigo 12, $\S 2^{\circ}$ ). O $\S 3^{\circ}$ do artigo 14 do Decreto $n^{0} 52.795 / 1963$, com redação dada pelo Decreto n ${ }^{\circ}$ 2.108, de 24.12.1996, também veda a mesma entidade ou as pessoas 
que integram o seu quadro societário e diretivo de serem contempladas com mais de uma outorga do mesmo tipo de serviço de radiodifusão na mesma localidade.

Ainda no $\S 7^{\circ}$ do Art. 12 do Decreto-Lei 236/67 há vedação de que as empresas concessionárias ou permissionárias de serviço de radiodifusão estejam subordinadas a outras entidades que se constituem com a finalidade de estabelecer direção ou orientação única, através de cadeias ou associações de qualquer espécie.

Entretanto, a interpretação dada pelo Ministério das Comunicações tornou tais limitações praticamente inócuas, pois: "considera 'entidade' como significando 'pessoa física' e, ademais, não leva em conta o parentesco"; "em relação ao parágrafo $7^{\circ}$, o Ministério das Comunicações não considera as 'redes' - formadas com a 'afiliação' contratual de emissoras - como constituindo subordinação 'com a finalidade de estabelecer direção ou orientação única' (Lima, 2011, p. 86). A própria ANCINE (2015, p. 26), ao divulgar o estudo "TV Aberta no Brasil: aspectos econômicos e estruturais", reconhece que as limitações existentes não afastaram a possibilidade de concentração de concessões e autorizações de radiodifusão.

Note-se, ainda, que, em 28 de março de 2017, foi publicada a Lei $\mathrm{n}^{\mathrm{o}} 13.424$, resultado da Conversão da Medida Provisória $n^{\circ}$ 747, de 2016, que altera as Leis n. 5.785, de 23 de junho de 1972, 9.612, de 19 de fevereiro de 1998, 4.117, de 27 de agosto de 1962, 6.615, de 16 de dezembro de 1978, para dispor sobre o processo de renovação do prazo das concessões e permissões dos serviços de radiodifusão, desconfigurando e flexibilizando a já parca regulação legal do setor.

Conforme explicado por Stroppa (2017, p. 237-239) pelas novas regras fixadas no art. $3^{\circ}$, as entidades cujas concessões ou permissões se encontrem vencidas e que não tenham apresentado seus pedidos de renovação dentro do prazo poderão fazê-lo no prazo de noventa dias, contado da data de sanção desta Lei, desde que não tenha havido manifestação do Congresso Nacional na forma estabelecida no $\S 2^{\circ}$ do art. 223 da Constituição Federal.

Mesmo aquelas emissoras que já tiveram as suas outorgas declaradas peremptas terão o prosseguimento do pedido de renovação, caso o Congresso Nacional ainda não tenha se manifestado sobre o caso (art. $2^{\circ}$, parágrafo único). Ainda, as entidades que não apresentarem pedido de renovação no prazo de doze meses que antecede o final da outorga serão notificadas pelo órgão competente do Poder Executivo para que se manifestem no prazo de noventa dias, contado da data da notificação (Art. 4, §3 ${ }^{\circ}$ da Lei $n^{0} 5.785 / 1972$ com a redação dada pela Lei No $\left.13.424 / 2017\right)$.

Outra alteração promovida foi a revogação das alíneas a, b e c do Art. 34 do Código Brasileiro de Telecomunicações (Lei $n^{\circ} 4.117$, de 27 de agosto de 1962) que exigiam dos candidatos à concessão: prova de idoneidade moral; demonstração dos recursos técnicos e financeiros de que dispõem para o empreendimento; a indicação dos responsáveis pela orientação intelectual e administrativa da entidade. Além disso, foi excluído do texto da referida lei $\left(\S 3^{\circ}\right.$ do Art. 33) a exigência de cumprimento de "todas 
as obrigações legais e contratuais" e o atendimento "ao interesse público" como requisito para o direito à renovação das outorgas.

Ainda, a Lei $\mathrm{n}^{\mathrm{o}}$ 13.424/2017 retirou a exigência, que constava na alínea c do Art. 38 da Lei 4.117/62 de prévia autorização do Poder Executivo para qualquer alteração nos objetivos sociais das empresas concessionárias, assim como de cessões de cotas e de ações que alterassem o controle societário das empresas, inclusive para as outorgas que estiverem funcionando em caráter precário, isto é, que ainda não tiveram os seus processos de renovação concluídos.

Como exemplo de inação, o Conselho de Comunicação Social, criado por lei específica, pode ser citado, pois vem recebendo críticas em trabalhos acadêmicos, tendo em vista o estado de ociosidade em determinados momentos da sua história (Simis, 2010), da ausência de participação da sociedade da sociedade civil, sendo que atores privilegiados dominam as discussões no Conselho (Marques, 2015), bem como pode ainda ser considerado letra morta (Jambeiro, 2009).

Em relação à classificação indicativa, conforme visto acima, não houve até o presente momento a edição de lei reguladora por parte do Congresso Nacional, excetuada a referência trazida na lei 12.485/2011. Ademais, em 31 de agosto de 2016, o Supremo Tribunal Federal (STF) declarou a inconstitucionalidade (ADI 2404) de artigo do Estatuto da Criança e do Adolescente que previa penalidades para a exibição de programas audiovisuais fora do horário estabelecido por portaria de classificação indicativa. Essa decisão do STF, ao definir que a classificação indicativa é mera indicação, sem possibilidade de restrição ou de penalização, torna-a vazia. A decisão do STF tornou a política pública de comunicação de classificação indicativa, prevista constitucionalmente, sem efeito prático.

Em relação à possibilidade de definição de mecanismos legais que garantam à pessoa e à família a possibilidade de se defenderem de programas ou programações de rádio e televisão nocivos ou contrários aos preceitos constitucionais, muito embora tenha havido a edição de leis reguladoras, tal política pública está sendo ineficaz. A lei 10.359/2001, por exemplo, que tratou da obrigatoriedade de aparelhos de televisão conterem dispositivo que possibilite o bloqueio temporário de recepção de programação inadequada, os conhecidos V-chips, ainda não saiu do papel. Essa afirmação ficou confirmada no voto do Ministro Dias Toffoli na ADI 2404 que tratou da classificação indicativa ${ }^{\text {iii. }}$ Verifica-se um exemplo claro de descaso em relação às normas vigentes relacionadas às políticas públicas de comunicação.

Ainda a despeito da existência de norma reguladora da propaganda comercial nociva à saúde, considera-se aqui que ela atende apenas parcialmente o que foi desejado pelo legislador constituinte.

Como já dito, a lei 9.294/96 regulou apenas parcialmente a matéria. Tendo em vista essa regulação apenas parcial, a referida lei foi questionada em três oportunidades junto ao STF (ADI 1755, ADO 22 e ADPF 333iv). O cerne da questão na ADI era de que 
a lei não poderia excluir as bebidas com teor alcoólico inferior a $13^{\circ}$ Gay Lussac da incidência da norma, tratando-se de uma discriminação desarrazoada, considerando que a finalidade da norma é proteger a saúde das pessoas e das famílias, portanto, essa exclusão seria inconstitucional.

A ADO buscava o reconhecimento da omissão legislativa parcial, tendo em vista a ausência prolongada de regulamentação acerca da propaganda de bebidas de teor alcoólico inferior a treze graus Gay Lussac. Por sua vez, a ADPF buscava a revisão de decisão de tribunal inferior que reconhecia implicitamente a revogação tácita da lei 9.294/96 pela lei 11.705/2008, ampliando-se com essa decisão as restrições de comerciais de bebidas alcoólicas para bebidas com teor alcoólico inferior a treze graus Gay Lussac. Em todas as oportunidades, o STF manifestou-se pela manutenção da regra prevista na lei 9.294/96, mantendo com isso as propagandas de cerveja em horários que crianças e adolescentes assistem à televisão. Crianças e adolescentes sabidamente são considerados grupos vulneráveis e mais sujeitos às influências de propagandas.

O STF também reconheceu, no julgamento da ADI 869-2, a inconstitucionalidade da expressão "ou a suspensão da programação da emissora até por dois dias, bem como da publicação do periódico por dois números" constante no $\S 2^{\circ}$ do Art. 247 da lei $n^{\circ}$ 8.069/90 (Estatuto da Criança e do Adolescente) por entender, nos termos do voto do Rel. Min. Ilmar Galvão, "não se tratar de providência tolerada pela Constituição ainda que implicitamente, como limitação plausível ao direito à manifestação do pensamento, mais precisamente ao direito à informação jornalística".

Na mesma senda, entendendo que o Constituinte proibiu a prática de censura de uma maneira ampla e não apenas as possíveis restrições vindas de autoridades administrativas ( $\S 2^{\circ}$ do Art. 220), o STF julgou procedente a:

a) ADI 4815 (STF, 2015, p. 3), para dar interpretação conforme à Constituição aos arts. 20 e 21 do Código Civil, sem redução de texto, para, em consonância com os direitos fundamentais à liberdade de pensamento e de sua expressão, de criação artística, produção científica, declarar inexigível autorização de pessoa biografada relativamente a obras biográficas literárias ou audiovisuais, sendo também desnecessária autorização de pessoas retratadas como coadjuvantes (ou de seus familiares, em caso de pessoas falecidas ou ausentes).

b) ADI 4451 para declarar inconstitucionais dispositivos da Lei das Eleições (lei 9.504/1997) que impediam emissoras de rádio e televisão de veicular programas de humor envolvendo candidatos, partidos e coligações nos três meses anteriores ao pleito, como forma de evitar que fossem ridicularizados ou satirizados (incisos II e III (em parte) do artigo 45 da Lei das Eleições);

c) ADI 2566 para declarar a inconstitucionalidade do $\S 1^{\circ}$ do Art. $4^{\circ}$ da Lei 9.612/98 sob alegação de impedir a livre manifestação de pensamento e de crença religiosa, violando os artigos $5^{\circ}$, incisos IV, VI e IX e o 220 da $\mathrm{CF} / 88$ ao vedar o 
proselitismo de qualquer natureza na programação das emissoras de radiodifusão comunitária.

Há tentativas de regulação do artigo 221, conforme determinado pela CF, no entanto, como indicam Santos e Napolitano (2016, p. 9), a tramitação de projeto no Congresso Nacional (Projeto de Lei 1441 de 2015, de autoria da Deputada Federal Jandira Feghali - PCdoB, por exemplo) remontam ao ano de 1991, portanto, há décadas tem havido esforços, contudo, não suficientes "para mudar o padrão da radiodifusão no Estado brasileiro haja vista a demora na aprovação do projeto de lei”.

No Art. 223 existe a imposição de observância do princípio da complementaridade entre os sistemas privado, público e estatal como vetor fundamental para a outorga e renovação das concessões, permissões e autorizações no campo dos serviços de radiodifusão sonora e de sons e imagens. Assim os canais públicos não se confundem com os veículos de órgãos estatais (como a TV Justiça, a TV Câmara e a NBR) tampouco buscam o lucro como os canais privados.

Nesse ponto, houve a promulgação da Lei $\mathrm{n}^{\mathrm{o}} 11.652 / 2008$, que institui os princípios e objetivos dos serviços de radiodifusão pública explorados pelo Poder Executivo ou outorgados a entidades de sua administração indireta; autoriza o Poder Executivo a constituir a Empresa Brasil de Comunicação - EBC e dá outras providências. A EBC foi definida como empresa pública federal de comunicação, com o objetivo de prestar uma comunicação pública desvinculada dos governos e sem interesse lucrativo. Ocorre que, em 01 de março de 2017, houve conversão da Medida Provisória 744/2016 na Lei 13.417. Referida legislação alterou a lei que criou a Empresa Brasil de Comunicação (EBC) e consolidou um verdadeiro esvaziamento do caráter público da empresa (Alarcón \& Stroppa, 2016).

É pertinente citar também a Lei 9.612/1998 que criou o Serviço de Radiodifusão Comunitária (RadCom) e que foi regulamentada pelo Decreto $\mathrm{n}^{\circ} 2.615 / 1998$. A rádio comunitária é considerada como uma espécie de serviço público e definida como "a radiodifusão sonora, em frequência modulada, operada em baixa potência e cobertura restrita, outorgada a fundações e associações comunitárias, sem fins lucrativos, com sede na localidade de prestação do serviço" (Art. $1^{\circ}$ ). Já, os canais de TV educativos são regidos pelo decreto-lei 236/67 que trata da televisão educativa e pela lei no 8.977/95 (Lei da TV a Cabo), que impõe às operadoras a disponibilização de canais de cunho universitário, educativo-cultural e comunitário.

Em relação à definição clara do sistema tripartite de concessão de emissoras de radiodifusão para o setor privado, público e estatal, bem como o estabelecimento de regras específicas sobre monopólio, oligopólios, propriedade cruzada, dentre outras questões que inibem a democratização da comunicação social, a proposta de 2012 do Fórum Nacional pela Democratização da Comunicação - FNDC pode ser considerada um modelo a ser seguido. Trata-se de acordo com Rothberg, Napolitano e Stroppa (2016, p. 92) de um "anteprojeto de lei de iniciativa popular da comunicação social eletrônica" que “objetiva regulamentar os artigos 5, 21, 22, 220 a 224 da Constituição Federal” e propõe, dentre outras regras a "organização dos serviços e estabelecimento de critérios de 
outorga", estabelecimento de "mecanismos para impedir a concentração no setor" e para "incentivo à diversidade", bem como a "definição de órgãos reguladores e criação do Conselho Nacional de Políticas de Comunicação." No entanto, tal proposta ainda é apenas um anteprojeto de lei, não havendo no âmbito do Congresso Nacional uma mobilização política para o início da tramitação do processo legislativo.

A inércia do Estado brasileiro, em especial, do Legislativo em regular as políticas públicas de comunicação também fica comprovada pelo ajuizamento de ações diretas de inconstitucionalidade por omissão no STF que visam a declaração da omissão do Congresso Nacional em legislar sobre a matéria. Trata-se das ADOs 10 e 11, de idêntico teor, a primeira patrocinada pelo Partido Socialismo e Liberdade (PSOL) e a segunda pela Confederação Nacional dos Trabalhadores em Comunicação e Publicidade. Ambas estão em trâmite no STF desde 2010, o que pode evidenciar também a falta de interesse do Judiciário brasileiro em enfrentar essa questão.

A lei 10.610/2002, que trata da participação de capital estrangeiro em empresas de comunicação, também está sendo questionada no STF pela Associação Nacional de Jornais - ANJ, na ADI 5613 e objetiva esclarecer qual é a amplitude do conceito de empresa jornalística, bem como a aplicação de restrições ao capital estrangeiro. Esse questionamento visa à aplicação de restrições às mídias digitais, hoje controladas pelo capital estrangeiro. O ajuizamento da ação ocorreu em outubro de 2016 e até o momento, quase dois anos após o protocolo, a ação não saiu do lugar, continua com o relator do processo Ministro Celso de Mello.

A seguir serão apresentadas algumas considerações em sede de conclusão.

\section{Conclusões}

Pelo que foi visto nas seções antecedentes, verifica-se que a despeito da exigência constitucional de regulações das políticas públicas de comunicação através de leis infraconstitucionais, o que se observa é uma inércia do Estado brasileiro, revestida até mesmo de desinteresse, indicando-se que poucos avanços foram alcançados, tendo em vista a ausência de normas como no caso citado da classificação indicativa, por exemplo.

Já quanto ao regramento da propaganda de bebidas alcoólicas, houve regulação parcial, sendo essa decisão política referendada pelo Supremo Tribunal Federal.

Mesmo havendo leis regulamentadoras, fica evidente a inoperância de determinados agentes, como a do Conselho de Comunicação Social que recebe sistematicamente críticas acerca de suas inações.

Algumas políticas públicas também foram desfiguradas e flexibilizadas por ações legislativas, como a das renovações de outorgas de concessões e permissões e a conversão da Medida Provisória que desfigurou o caráter público da Empresa Brasil de Comunicação ou por interpretações conferidas pelo Executivo, no caso específico dos 
limites de propriedade de emissoras, evidenciando-se retrocessos nas políticas públicas de comunicação.

O Supremo Tribunal Federal, em especial, também corrobora esse estado de inércia ao protelar o julgamento de ações acerca das políticas públicas de comunicação, citando-se aqui as ADOs 10 e 11 que buscam o reconhecimento da inconstitucionalidade das omissões legislativas para o setor. Por outro lado, reconhece a inconstitucionalidade de legislações que restringem a amplitude por ele conferida à liberdade de expressão do pensamento e de informação jornalística, como no reconhecimento da inconstitucionalidade da proibição de proselitismo em rádios comunitárias.

O Estado brasileiro como um todo e como visto contribui para a anomia do setor, com omissões sistemáticas do Congresso Nacional, amparado pela conivência e conveniência do Executivo Federal e a complacência do Supremo Tribunal Federal, considerando-se aqui que a regulação das políticas públicas de comunicação, tal como prevista no texto constitucional, é mais um desafio futuro que exige a sedimentação da própria ideia da necessidade de uma regulação voltada para o amadurecimento democrático da sociedade brasileira, proposta que vai muito além da escassa e, às vezes, desvirtuada atuação estatal nesses trinta anos posteriores à promulgação da Constituição vigente.

\section{Referências}

Alarcón, P. de J. L \& Stroppa, T. (2016). A inconstitucionalidade da Medida Provisória 744, o princípio da complementariedade e o desmonte da comunicação pública brasileira. Recuperado de http://emporiododireito.com.br/leitura/ainconstitucionalidade-da-medida-provisoria-744-o-principio-dacomplementariedade-e-o-desmonte-da-comunicacao-publica-brasileira.

Agência Nacional do Cinema (ANCINE). (2015). TV Aberta no Brasil: aspectos econômicos e estruturais. Recuperado de http://oca.ancine.gov.br/sites/default/files/televisao/pdf/Estudo_TVAberta_2015. pdf

Brasil. Supremo Tribunal Federal. (1993). Ação direta de inconstitucionalidade n. 869, de 06 de maio de 1993. Recuperado de http://www.stf.jus.br/portal/processo/pesquisarProcesso.asp

Brasil. Supremo Tribunal Federal. (1997). Ação direta de inconstitucionalidade n. 1755, de 22 de dezembro de 1997. Recuperado de http://www.stf.jus.br/portal/processo/pesquisarProcesso.asp. 
Brasil. Supremo Tribunal Federal. (2001a). Ação direta de inconstitucionalidade n. 2404, de 06 de fevereiro de 2001a. Recuperado de http://www.stf.jus.br/portal/processo/pesquisarProcesso.asp.

Brasil. Supremo Tribunal Federal. (2001b). Ação direta de inconstitucionalidade n. 2566, de 10 de novembro de 2001b. Recuperado de http://www.stf.jus.br/portal/processo/pesquisarProcesso.asp.

Brasil. Supremo Tribunal Federal. (2004). Ação direta de inconstitucionalidade n. 3311, de 24 de setembro de 2004. Recuperado de http://portal.stf.jus.br/processos/detalhe.asp?incidente=2246660.

Brasil. Supremo Tribunal Federal. (2010). Ação direta de inconstitucionalidade n. 4451, de 24 de agosto de 2010. Recuperado de http://www.stf.jus.br/portal/processo/pesquisarProcesso.asp.

Brasil. Supremo Tribunal Federal. (2011). Ação direta de inconstitucionalidade n. 4679, de 18 de novembro de 2011. Recuperado de http://www.stf.jus.br/portal/processo/pesquisarProcesso.asp.

Brasil. Supremo Tribunal Federal. (2012a). Ação direta de inconstitucionalidade n. 4747, de 28 de março de 2012a. Recuperado de http://www.stf.jus.br/portal/processo/pesquisarProcesso.asp.

Brasil. Supremo Tribunal Federal. (2012b). Ação direta de inconstitucionalidade n. 4756, de 04 de abril de 2012b. Recuperado de http://www.stf.jus.br/portal/processo/pesquisarProcesso.asp

Brasil. Supremo Tribunal Federal. (2012c). Ação direta de inconstitucionalidade n. 4815, de 05 de julho de 2012c. Recuperado de http://www.stf.jus.br/portal/processo/pesquisarProcesso.asp.

Brasil. Supremo Tribunal Federal. (2013). Ação direta de inconstitucionalidade n. 4923, de 20 de março de 2013. Recuperado de http://www.stf.jus.br/portal/processo/pesquisarProcesso.asp.

Brasil. Supremo Tribunal Federal. (2016). Ação direta de inconstitucionalidade n. 5613, 20 de outubro de 2016. Recuperado de http://www.stf.jus.br/portal/processo/pesquisarProcesso.asp.

Brasil. Supremo Tribunal Federal. (2010a). Ação direta de inconstitucionalidade por omissão $n$. 10, de 11 de novembro de 2010a. Recuperado de http://www.stf.jus.br/portal/processo/pesquisarProcesso.asp.

Brasil. Supremo Tribunal Federal. (2010b). Ação direta de inconstitucionalidade por omissão $n$. 11, de 10 de dezembro de 2010b. Recuperado de http://www.stf.jus.br/portal/processo/pesquisarProcesso.asp. 
Brasil. Supremo Tribunal Federal. (2012). Ação direta de inconstitucionalidade por omissão n. 22, de 12 de dezembro de 2012. Recuperado de http://www.stf.jus.br/portal/processo/pesquisarProcesso.asp.

Brasil. Supremo Tribunal Federal. (2008). Arguição de descumprimento de preceito fundamental $n$. 130, de 10 de fevereiro de 2008. Recuperado de http://www.stf.jus.br/portal/processo/pesquisarProcesso.asp.

Brasil. Supremo Tribunal Federal. (2011). Arguição de descumprimento de preceito fundamental $n$. 246, de 15 de dezembro de 2011. Recuperado de http://www.stf.jus.br/portal/processo/pesquisarProcesso.asp.

Brasil. Supremo Tribunal Federal. (2015). Arguição de descumprimento de preceito fundamental $n$. 333, de 26 de fevereiro de 2015a. Recuperado de http://portal.stf.jus.br/processos/downloadPeca.asp?id=306937445\&ext=.pdf.

Brasil. Supremo Tribunal Federal. (2015b). Arguição de descumprimento de preceito fundamental $n$. 379, de 01 de dezembro de 2015b. Recuperado de http://www.stf.jus.br/portal/processo/pesquisarProcesso.asp.

Brasil. Supremo Tribunal Federal. (2016). Arguição de descumprimento de preceito fundamental n. 429, de 09 de novembro de 2016. Recuperado de http://portal.stf.jus.br/processos/detalhe.asp?incidente $=5088869$.

Bucci, M. P. D. (2006). O conceito de política pública em direito. En: Bucci, M. P. D. (Ed.) Políticas públicas: reflexões sobre o conceito jurídico (pp. 1-47). São Paulo: Saraiva.

Bucci, M. P. D. (2008). Notas para uma metodologia jurídica de análise de políticas públicas. En: Forini, C.; Esteves, J. C. dos S. \& Dias, M. T. F. (Ed.). Políticas públicas: possibilidade e limites (pp. 225-260). Belo Horizonte: Fórum.

Bucci, M. P. D. (2013). Fundamentos para uma teoria jurídica das políticas públicas. São Paulo: Saraiva.

Coutinho, D. R. (2013). O direito nas políticas públicas. En: Marques, E \& Faria, C. A. P. de (Ed.). A política pública como campo multidisciplinar. (pp. 180-200). São Paulo: Ed. UNESP; Rio de Janeiro: Ed. Fiocruz.

Grau, E. R. (2003). O direito posto e o direito pressuposto. 5 ed. São Paulo: Malheiros.

Jambeiro, O. (2009). A comunicação na Constituição de 1988. En: Goulart, J. O. (Ed.) As múltiplas faces da Constituição cidadã (pp. 133-134). São Paulo: Cultura Acadêmica.

Lima, V. A. de. (2011). Regulação das comunicações: história, poder e direitos. São Paulo: Paulus. 
Napolitano, C. J. (2017). Contribuições do Direito para a análise das políticas públicas de comunicação. Líbero, São Paulo, (40), pp. 1-16.

Marques, P. C de M. (2015). A participação e a representação no Conselho de Comunicação Social. (Dissertação). Universidade Estadual Paulista, Faculdade de Arquitetura, Artes e Comunicação, Programa de Pós-Graduação em Comunicação, Bauru.

Rothberg, D.; Napolitano, C. J. \& Stroppa, T. (2016). Direito, sociedade e comunicação: um exame do anteprojeto de lei da mídia democrática no Brasil. Comunicação e Sociedade, (30), pp. 87-102.

Santos, A. J. S. \& Napolitano, C. J. (2016). Teoria democrática e Doutrina da Equidade na Regulamentação da Comunicação Social: articulações com o Projeto de Lei 1441/2015 do Legislativo Federal Brasileiro. En: Intercom Sudeste, Salto. Anais Intercom Sudeste. Sudeste: Intercom, (1), pp. 1-12.

Simis, A. (2010). Conselho de Comunicação Social: uma válvula para o diálogo ou para o silêncio? Revista Brasileira de Ciências Sociais, (25), pp. 59-71.

Stroppa, T. (2017). Regulação da TV Aberta: censura ou contribuição para a democracia? En: Leão júnior, T. M. de A; Pancotti, L. G. B \& Pitta, R. G. (Ed.). Sistema Constitucional de Garantia de Direitos II. 1. ed. - Jacarezinho, PR: UENP, pp. 225-248. Recuperado de http://siacrid.com.br/repositorio/2017/sistemaconstitucional-de-garantia-de-direitos-II.pdf

\section{Notas}

i A lei 13.188/2015 regulou o direito de resposta.

ii Muito embora a lei 12.485/2011 que dispõe sobre a comunicação audiovisual de acesso condicionado impôs em seu artigo 11, in verbis: "Nenhum conteúdo veiculado por meio do Serviço de Acesso Condicionado será exibido sem aviso, antes de sua apresentação, de classificação informando a natureza do conteúdo e as faixas etárias a que não se recomende".

iii Na oportunidade, o Ministro assim se manifestou: "De início, essa lei entraria em vigor um ano após sua publicação, com o intuito de permitir que os fabricantes de televisão se adaptassem à produção desses aparelhos. Posteriormente, no entanto, a Medida Provisória $\mathrm{n}^{\circ}$ 79, de 27 de novembro de 2002, convertida na Lei $\mathrm{n}^{\circ} 10.672$, de 15 de maio de 2003, postergou o início da vigência da Lei $\mathrm{n}^{\circ} 10.359 / 01$ para 30 de junho de 2004. Não bastante, em junho de 2004, foi editada a Medida Provisória no 195 , de 29 de junho de 2004, revogando a Lei $\mathrm{n}^{\circ}$ 10.359/01 e estabelecendo nova disciplina acerca da matéria, além de estabelecer que a data de exigência desse sistema não poderia ser posterior a 31 de outubro de 2006 (art. $2^{\circ}$, $1^{\circ}$ ). Ocorre que essa medida provisória foi rejeitada pelo Senado Federal, de modo que foram restauradas as disposições da Lei $\mathrm{n}^{\circ}$ 10.359, de 2001. Resumindo: o dispositivo eletrônico que permite ao usuário bloquear a recepção de programas transmitidos pelas emissoras, concessionárias e permissionárias de serviços de televisão voltou a ser obrigatório desde 30 de junho de 2004, embora essa obrigatoriedade seja, até hoje, totalmente ignorada." (BRASIL, 2016)

iv Cite-se, ainda, a ADI 3311, não julgada, proposta pela Confederação Nacional da Indústria para requerer a declaração de inconstitucionalidade do caput e $\S \S 2^{\circ}, 3^{\circ}, 4^{\circ}$ e $5^{\circ}$ da Lei 9.294/96, em relação às restrições impostas às propagandas de produtos derivados de tabaco. 